\title{
Synthesis and Utilization of $\alpha$-Substituted Nitroxides
}

\author{
Toshihide Yamasaki, Fumiya Mito, Yuta Matsuoka, \\ Mayumi Yamato and Ken-ichi Yamada
}

Additional information is available at the end of the chapter

http://dx.doi.org/10.5772/39163

\section{Introduction}

Nitroxides are stable free radicals which have the $>\mathrm{N}-\mathrm{O}$ moiety. In most cases, nitroxides have a ring structure. For example, imidazoline, isoindoline, piperidine and pyrrolidine ring nitroxides (Fig. 1) have been used as agents for spin labeling, imaging, and as antioxidants. These nitroxides have four substituents at the $\alpha$-position; two substituents on each $\alpha$-carbon. All four substituents are needed for avoiding the disproportionation reaction of nitroxides except for the case of a bridgehead at the $\alpha$-position. Methyl groups have been chosen as simple and inert substituents. However, it has been reported that other types of substituents, especially ethyl groups, showed unique characteristics that were unlike those of the conventional methyl group.

In this chapter, we will introduce the conventional as well as the latest synthetic methods used to introduce the various substituents to the $\alpha$-position. Also, we will describe the structure-reactivity relationships of $\alpha$-substituted nitroxides.

\section{Synthetic methods of $\alpha$-substituted nitroxides}

\subsection{Imidazoline}

Imidazoline nitroxides have been synthesized from $\alpha$-hydroxyaminoketone with carbonyl compounds (Scheme 1) (Volodarsky and Igor A, 1988). The $R_{1}$ groups of $\alpha$ hydroxyaminoketone and $\mathrm{R}_{2}$ groups of carbonyl compounds correspond to the $\alpha$-position of the imidazoline ring. $\alpha$-Hydroxyaminoketones are synthesized from appropriate olefines via nitrosylation, treatment with hydroxylamine, and hydrolysis (Kirilyuk et al., 2004). This is a practical method because this key compound can be synthesized on the gram scale. For $\mathrm{R}_{2}$ groups, chain ketones or cyclic alkyl ketones are used as carbonyl 
compounds (Bobko et al., 2007; Kirilyuk et al., 2004; Yan'shole et al., 2010; Zubenko et al., 2006). These give the 2,2,5,5-tetrasubstituted 2,5-dihydro- $1 H$-imidazole-1-ol. After oxidation, they give the desired imidazole nitroxides. Imidazolidine nitroxides can be synthesized from imidazoline nitroxides by reduction (Zubenko et al., 2006). Therefore, $\alpha$ substituted imidazoline nitroxides are also synthesized from $\alpha$-substituted imidazolidine nitroxides.

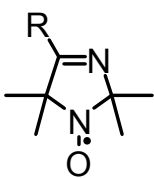

imidazoline<smiles>[R]C1CC(C)(C)N([O-])C(C)(C)C1</smiles>

piperidine

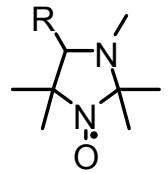

imidazolidine

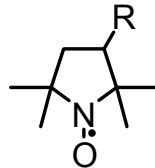

pyrrolidine

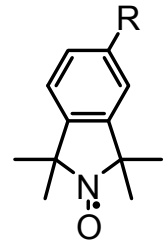

isoindoline

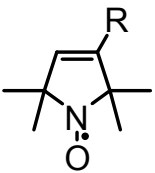

pyrroline

Figure 1. Basic structure of nitroxides

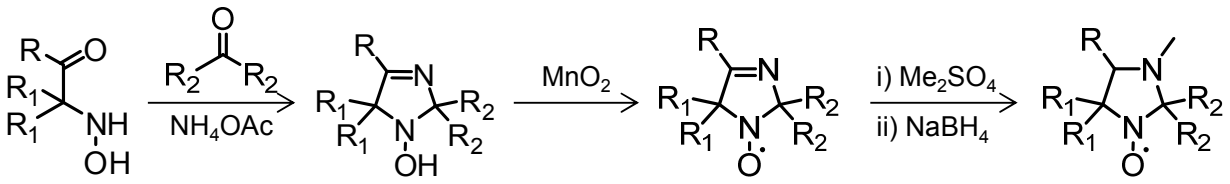

Scheme 1. $\alpha$-Substitution synthesis of imidazoline and imidazolidine nitroxides

$$
\begin{aligned}
& \mathrm{R}_{1}=\mathrm{Me} ; \mathrm{R}_{2}=\mathrm{Me}, \mathrm{Et}, \mathrm{n}-\mathrm{Bu},\left(\mathrm{CH}_{2}\right)_{4},\left(\mathrm{CH}_{2}\right)_{5} \\
& \mathrm{R}_{1}=\mathrm{Et} ; \mathrm{R}_{2}=\mathrm{Me}, \mathrm{Et},\left(\mathrm{CH}_{2}\right)_{5},\left(\mathrm{CH}_{2}\right)_{2} \mathrm{COONa}
\end{aligned}
$$

\subsection{Isoindoline}

Isoindoline nitroxides have been prepared by the addition of a greater than fourfold excess of a single Grignard reagent to $N$-benzylphthalimide (Scheme 2) (Griffiths et al., 1983). Therefore, according to the type of Grignard reagent, various substituents can be introduced to the $\alpha$-position of the nitroxide moiety (Chan et al., 2010). Corresponding 2-benzyl-1,1,3,3tetrasubstituted isoindoline derivatives are then deprotected and subsequent oxidation gives the $\alpha$-substituted isoindoline nitroxides. The isoindoline skeleton has the potential to have low solubility in water; longer alkyl chains cause a decrease in water solubility. Hence, many studies have been conducted with ethyl groups with respect to biological applications (Fairfull-Smith et al., 2009; Marx et al., 2000). 


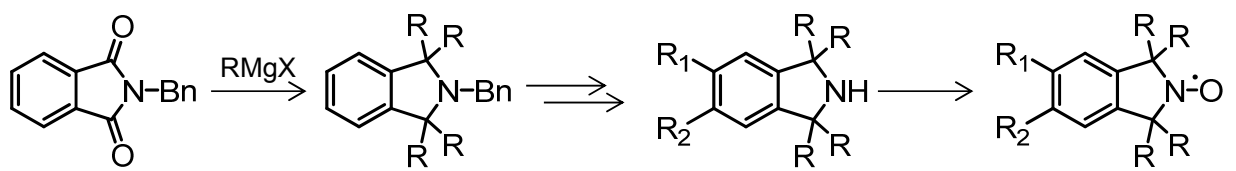

Scheme 2. $\alpha$-Substitution synthesis of isoindoline nitroxides

$$
\mathrm{R}=\mathrm{Me}, \mathrm{Et}, \mathrm{n}-\mathrm{Pr}, \mathrm{n}-\mathrm{Bu}, \mathrm{Ph}
$$

\subsection{Piperidine}

Piperidine nitroxides have been synthesized by two main approaches. One is the synthesis from acetonin (2,2,4,4,6-pentamethyl-2,3,4,5-tetrahydropyrimidine) with carbonyl compounds (Schemes 3a and b). Murayama et al. reported the isolation of 1,9-diaza$2,2,8,8,10,10$-hexamethylspiro[5.5]undecan-4-one as a byproduct in the method development for 2,2,6,6-tetramethyl-4-piperidone (Murayama et al., 1969). Subsequently, using acetonin, various $\alpha$-substituted piperidine derivatives were reported by Ma et al. (Ma et al., 1993) and Miura et al. (Scheme 3b) (Mannan et al., 2007; Miura et al., 2003; Miura et al., 2001; Okazaki et al., 2007). These methods have the advantage of synthesis in a few steps, but the key compound used at the start of the synthesis, acetonin, lacks stability.

The other main approach is a stepwise synthesis from the appropriate starting material (Schemes 3c, d and e). For example, Yoshioka et al. reported on the synthesis for piperidine nitroxides having a spirocyclohexyl group via $\alpha$, $\beta$-unsaturated ketone derivatives (Yoshioka et al., 1972). In addition, focusing on substitution of the tetraethyl group, Studer et al. reported a stepwise synthesis via bisphosphonates (Wetter et al., 2004), and also $\beta$-lactams for obtaining piperidine nitroxides on a large scale (Schulte et al., 2005) which involved several synthetic steps and a high-pressure reactor.

Recently, an alternative synthetic method has been developed (Scheme 3f) (Sakai et al., 2010). This method involves 2,2,6,6-tetramethyl-4-piperidone as a starting compound; this compound is more stable than acetonin and is available commercially. This compound with cyclohexanone directly gave the piperidone derivative having spirocyclohexyl groups at the 2,6-position under a mild reaction condition. Moreover, the reaction yield was increased by using 1,2,2,6,6-pentamethyl-4-piperidone and a base. With this starting compound, various substituents have been introduced to the $\alpha$-position (Yamasaki et al., 2011; Yamasaki et al., 2010). From the investigation of the reaction mechanism, the nitrogen derived from ammonium chloride was introduced to the piperidone ring. Therefore, using ${ }^{15} \mathrm{~N}$-labeled $\mathrm{NH}_{4} \mathrm{Cl}$ instead of ${ }^{14} \mathrm{NH}_{4} \mathrm{Cl},{ }^{15} \mathrm{~N}$-labeled 2,2,6,6-tetrasubstituted piperidin-4-one-1-oxyls can be produced with high $(>98 \%){ }^{15} \mathrm{~N}$ content. Thus, the external $\mathrm{NH}_{4} \mathrm{X}$ compound seems to be the source of nitrogen during this reaction. 
a) acetone $+\mathrm{NH}_{3} \rightarrow \mathrm{C}_{\mathrm{H}}^{\mathrm{N}}$<smiles>CC1(C)CC2(CC(=O)CC(C)(C)N2)CC(C)(C)N1</smiles>

1,9-Diaza-2,2,8,8,10,10spiro[5.5]undecan-4-one

b) Acetonin $\stackrel{\bigcup_{[0 x]}}{\longrightarrow}$<smiles></smiles><smiles>C=C(C)C1CCC(C)C2(CC(=O)CC(C)(C)N2O)C1</smiles><smiles>CC1(C)CC(=O)CC12CCCCC2</smiles><smiles>CCC(=O)N1C(C)(C)CC(=O)CC12CCCC2</smiles>

c)<smiles>CC(C)=CC(=O)COc1ccc(CC(=O)C=C(C)C)cc1</smiles><smiles>CC(C)=O</smiles><smiles>O=CN1C2(CCCCC2)CC(=O)CC12CCCC(C(=O)C1C(=O)CC3(CCCCC3)NC13CCCCC3)C2</smiles>

d)

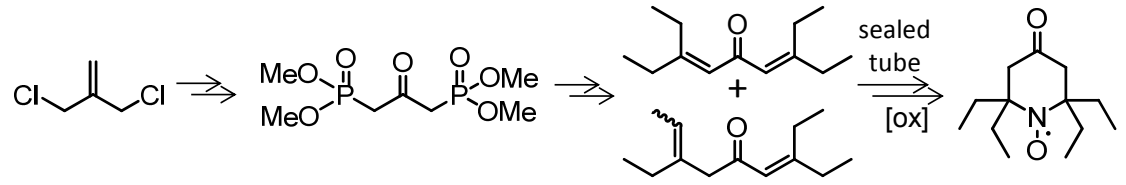

e)

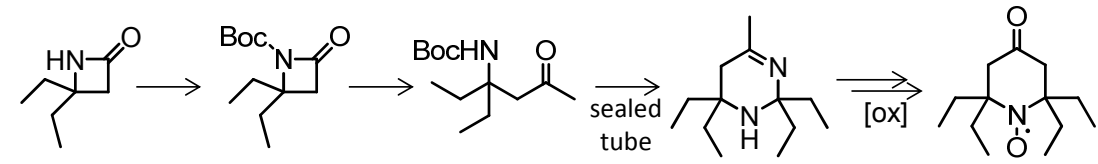

f)

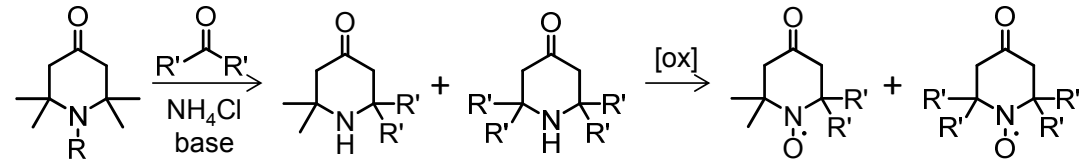

Scheme 3. $\alpha$-Substitution synthesis of piperidine nitroxides. a), b) from acetonin, c), d), e) stepwise synthesis, f) from piperidone 


\subsection{Pyrrolidine}

$\alpha$-Substituted pyrrolidine nitroxides has been synthesized via the nucleophilic addition of organometallic reagents such as 2,2,5-trimethyl-3,4-dihydro-2H-pyrrole-1-oxide or 2,5dimethyl-3,4-dihydro-2H-pyrrole-1-oxide to nitrone (Ikuma et al., 2004; Keana et al., 1983). Grignard reagents are also used as nucleophiles. These moieties are introduced to the $\alpha$ position of the nitroxide. Therefore, various substituents could be introduced depending on the organometallic reagent. Moreover, substitution of the starting 3,4-dihydro-2H-pyrrole-1oxide at the 2 and 5 positions has been carried out (Black et al., 2000). This also led to $\alpha$ substituted pyrrolidine nitroxides. These derivatives have been synthesized via intramolecular reductive amination from 5-nitrohexan-2-one derivatives. Additionally, the stepwise synthesis from 5-methylhex-5-en-2-one to introduce the phosphonate group has been reported (Le Moigne et al., 1991).
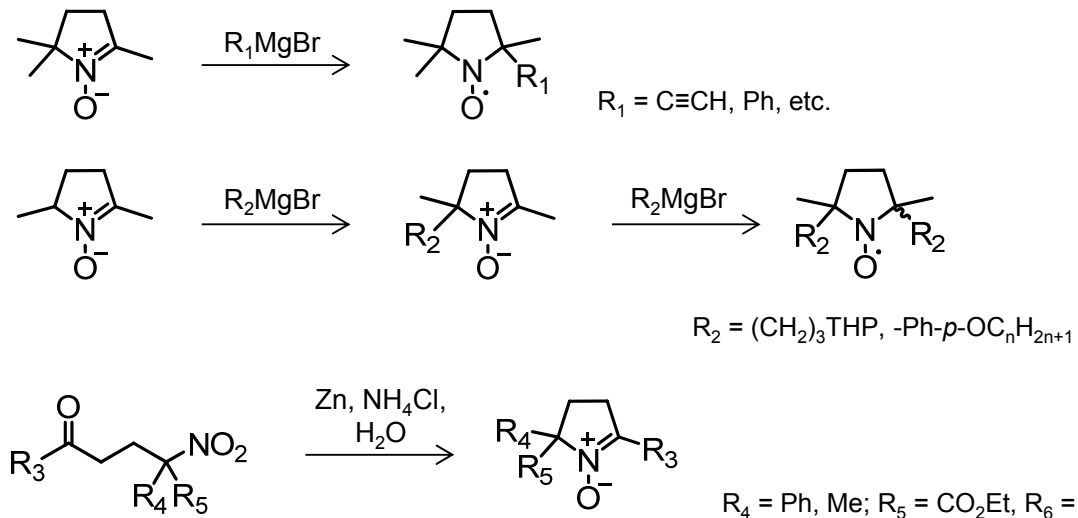

$\mathrm{R}_{4}=\mathrm{Ph}, \mathrm{Me} ; \mathrm{R}_{5}=\mathrm{CO}_{2} \mathrm{Et}, \mathrm{R}_{6}=\mathrm{CO}_{2} \mathrm{Et}, \mathrm{H}$

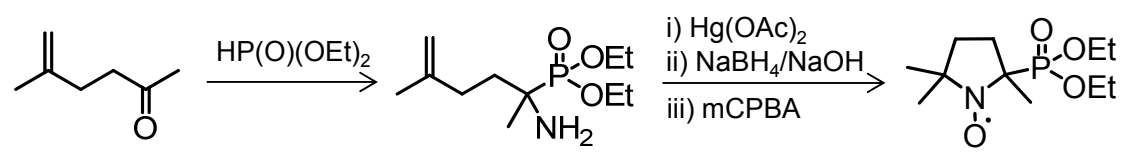

Scheme 4. $\alpha$-Substitution synthesis of isoindoline nitroxides

$$
\mathrm{R}=\mathrm{Me}, \mathrm{Et}, \mathrm{n}-\mathrm{Pr}, \mathrm{n}-\mathrm{Bu}, \mathrm{Ph}
$$

\section{Evaluation of $\alpha$-substituted nitroxides}

\subsection{Common reactivity of nitroxides}

Nitroxides have several potential advantages as spin probes (Kuppusamy et al., 2002; Yamada et al., 2006), spin labels (Borbat et al., 2001), contrast agents (Soule et al., 2007) and antioxidants (Wilcox and Pearlman, 2008). These applications are based on the complementary nature of the radical moieties in nitroxides; paramagnetism allows them to react with free radicals and interact with nuclear spin. For instance, these properties allow 
nitroxides to be used as contrast agents for magnetic resonance imaging (MRI) to give images of the morphological nature and redox imbalance in animal models of oxidative stress.

In biological systems, understanding of biophysical properties is helpful to promote effective utilization and control of the reactivity of nitroxides. Nitroxides are readily oxidized to oxoammonium cations or reduced to hydroxylamines by various in vivo oxidants or reductants (Fig. 2) (Kocherginsky and Swartz, 1995). Upon reaction with superoxides, nitroxides undergo one-electron oxidation and subsequent two-electron reduction with reductants, which is driven forward by the redox potential of the nitroxide redox couple (Krishna et al., 1992). Conversely, nitroxides are reduced by ascorbic acid and converted into hydroxylamines (Saphier et al., 2003). This effect is one of the limitations of using nitroxides for monitoring in vivo redox status because the lifetime in vivo is shortened. The reduction rate by ascorbic acid is dependent mainly upon their ring structures and substituent groups. The rate constants decrease in the order oxazolidines $>$ piperidines $>$ pyrrolines $>$ pyrrolidines, and the increasing inductive effects by the substituent group at the $\beta$ - or $\gamma$-positions of pyrrolidine and piperidine nitroxide also affect the rate (Kocherginsky and Swartz, 1995). In this section, the effect of $\alpha$-substituted nitroxides (especially piperidine nitroxide) on reduction by ascorbic acid was summarized and its in vivo application discussed.

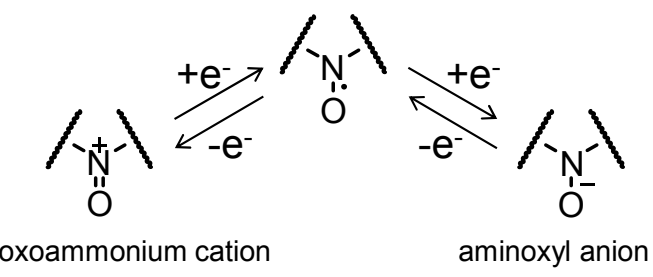

Figure 2. Redox couples of nitroxide

\subsection{Reduction stability}

As well as at $\beta$ - or $\gamma$-positions, substituent groups at $\alpha$-positions in a nitroxide ring can change their reactivity. For instance, phosphorylated pyrrolidinyl nitroxide showed moderate increase toward ascorbate reduction compared with the tetramethyl pyrrolidine nitroxide (Mathieu et al., 1997). On the other hands, the tetraethyl-substituted isoindoline (Marx et al., 2000), imidazoline (Kirilyuk et al., 2004), and imidazolidine (Kirilyuk et al., 2004) nitroxides showed high resistivity to ascorbate reduction than the corresponding tetramethyl compounds. Furthermore, Kirilyuk et al. reported that tetraethyl-substituted imidazoline nitroxides had significantly longer half-lives in rat blood samples as compared with the corresponding tetramethyl-nitroxides (Kirilyuk et al., 2004). Although piperidine nitroxides with spirocyclohexyl groups at $\alpha$-positions showed no difference in reactivity with ascorbic acid, the enzymatic reaction was efficiently protected (Okazaki et al., 2007). Recently, tetraethyl-substituted piperidine nitroxide was also reported to exhibit resistance 
to ascorbate reduction (Kinoshita et al., 2009). The electron spin resonance (ESR) or electron paramagnetic resonance (EPR) signal intensities of tetraethyl-substituted piperidine nitroxide remained $97 \%$ after ascorbate addition (Fig. 3). These reports indicated that the reduction rates of nitroxides vary significantly depending on their structure and microenvironment resulting from the $\alpha$-substitution of nitroxides. Tetraethyl-type nitroxides could be potentially useful for monitoring in vivo free-radical reactions, $\mathrm{pH}$ changes, and redox status without undesirable reduction by ascorbic acid.

Tetraethyl-nitroxides, having higher lipophilicity than tetramethyl compounds, have been reported to be less toxic to cells (Kinoshita et al., 2010) although the toxicity is reported to be correlated with the structure and lipophilicity of nitroxides (Ankel et al., 1987). Furthermore, single-dose administration of tetraethyl piperidine nitroxide has been shown to have lower blood pressure-lowering effects compared with that of Tempol (Kinoshita et al., 2010).

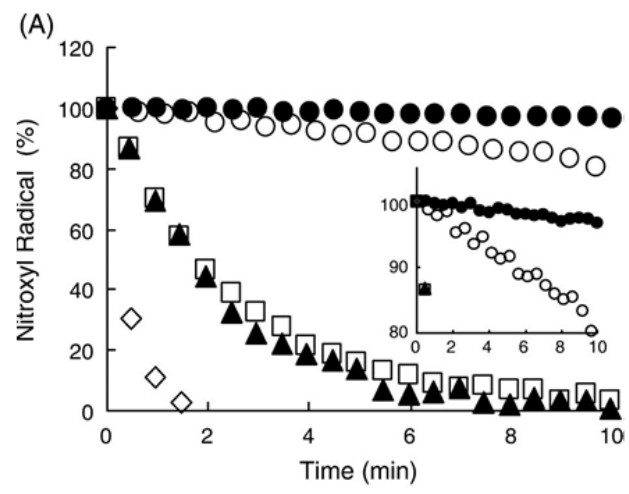

Figure 3. Effect of AsA on the decay of ESR signals of nitroxides. Nitroxides $(100 \mu \mathrm{M})$ were mixed with AsA $(1 \mathrm{mM})$ in phosphate buffered saline and their ESR spectra measured as a function of time. $\bullet$ :

4-oxo-2,2,6,6-tetraethyl-piperidine-1-oxyl; ०: carbamoyl-PROXYL; $\mathbf{\Lambda}$ : hydroxy-TEMPO (TEMPOL); $\square$ : oxo-TEMPO (TEMPONE); 0: 7-Aza-3,11-dioxa-15-oxodispiro[5.1.5.3] hexadec-7-yl-7-oxyl. (Kinoshita et al., Free Radic Res 2009;43: 565, copyright@ 2012, Informa Healthcare. Reproduced with permission of Informa Healthcare)

\subsection{Electrochemical behaviours}

The change in nitroxide reactivity due to the presence of tetraethyl substituents suggests that introduction of bulky alkyl groups at $\alpha$-positions in a nitroxide ring are responsible for their reduction stability. Steric hindrance around the radical moiety is one of the most important factors inhibiting access to reductants. However, the ESR signal intensities of 7Aza-3,11-dioxa-15-oxodispiro[5.1.5.3] hexadec-7-yl-7-oxyl (which has also bulky spirocyclohexyl rings at $\alpha$-positions) decrease rapidly in the presence of ascorbate 
<smiles>[R]C1([R])CC(=O)CC([R])([R])N1C=O</smiles><smiles>CCCC1(C)CCOCC1</smiles><smiles>[R]C1CC=NC2(CC1)CC(=O)C2</smiles><smiles>[R]CC1([R])CC(=O)CC12CC[R]N2O</smiles>

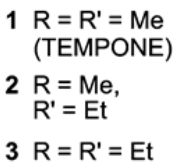<smiles>[R]C=C1CCCO1</smiles>

7a $\mathrm{R}=\mathrm{N}-\mathrm{Ac}$

8a $\mathrm{R}=\mathrm{SO}_{2}$ 7b $\mathrm{R}=\mathrm{N}-\mathrm{Ac}$

$\mathrm{R}^{\prime}=\mathrm{Me}$

8b $\mathrm{R}=\mathrm{SO}_{2}$

$\mathrm{R}^{\prime}=\mathrm{Me}$

8c $\mathrm{R}=\mathrm{SO}_{2}$ $\mathrm{R}^{\prime}=\mathrm{Et}$

Figure 4. Structure of $\alpha$-substituted piperidine nitroxides

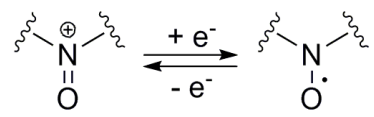

\begin{tabular}{cccccc} 
Nitroxide & $E_{p a}{ }^{b}$ & $E_{p c}{ }^{c}$ & $E^{l / 2 d}$ & $\Delta E^{e}$ & $i_{p a} / i_{p c}{ }^{f}$ \\
\hline $\mathbf{1}$ & 0.939 & 0.869 & 0.904 & 0.070 & 2.30 \\
$\mathbf{2}$ & 0.926 & 0.860 & 0.893 & 0.065 & 1.56 \\
$\mathbf{3}$ & 0.806 & 0.747 & 0.776 & 0.058 & 2.64 \\
& & & & & \\
$\mathbf{4}$ & 0.878 & 0.811 & 0.845 & 0.067 & 2.97 \\
$\mathbf{5}$ & 1.013 & 0.874 & 0.944 & 0.139 & 3.29 \\
$\mathbf{6}$ & 1.053 & 0.940 & 0.997 & 0.113 & 3.06 \\
$\mathbf{7 a}$ & 1.113 & $-g$ & - & - & - \\
$\mathbf{7 b}$ & 1.019 & 0.902 & 0.961 & 0.117 & 3.34 \\
$\mathbf{8 a}$ & 1.303 & $-g$ & - & - & - \\
$\mathbf{8 b}$ & 1.122 & 1.012 & 1.067 & 0.110 & 3.51 \\
$\mathbf{8 c}$ & 1.116 & 1.020 & 1.068 & 0.096 & 3.65
\end{tabular}

a glassy carbon electrode, $\mathrm{Ag} / \mathrm{AgCl}, \mathrm{Pt}$, sweep rate: $0.1 \mathrm{~V} \mathrm{~s}^{-1}$. Potentials were shown as vs. SHE. ${ }^{b}$ anodic peak potential. ${ }^{c}$ cathodic peak potential. ${ }^{d} E^{1 / 2}=\left(E_{p a}+E_{p c}\right) / 2 .{ }^{e} \Delta E=E_{p a}-E p c . f$ The peak currents $\left(i_{p a}\right.$ and $\left.i_{p c}\right)$ were measured from the respective baseline currents. 8 The current of the cathodic peak was too low to determine the potential value. Adapted with permission from (Yamasaki et al., J Org Chem 2011;76:435). Copyright (2012) American Chemical Society.

Table 1. Experimental redox potentials of oxoammonium cation / nitroxide redox couple ${ }^{a}$ 


\begin{tabular}{|c|c|c|c|c|c|}
\hline Nitroxide & $E_{p a}^{b}$ & $E_{p c}{ }^{c}$ & $E^{1 / 2 d}$ & $\Delta E^{e}$ & $i_{p a} / i_{p c} f$ \\
\hline 1 & 0.524 & -0.371 & 0.076 & 0.895 & 0.20 \\
\hline 2 & 0.453 & -0.401 & 0.026 & 0.854 & 0.20 \\
\hline 3 & 0.226 & -0.298 & -0.036 & 0.524 & 2.12 \\
\hline 4 & 0.244 & -0.141 & 0.051 & 0.385 & 0.99 \\
\hline 5 & 0.515 & -0.364 & 0.076 & 0.879 & 0.09 \\
\hline 6 & 0.644 & -0.386 & 0.129 & 1.029 & 0.19 \\
\hline $7 a$ & 0.613 & -0.247 & 0.183 & 0.860 & 0.27 \\
\hline $7 b$ & 0.585 & -0.381 & 0.102 & 0.967 & 0.31 \\
\hline $8 a$ & 0.653 & -0.357 & 0.148 & 1.010 & 2.18 \\
\hline $8 b$ & 0.694 & -0.494 & 0.100 & 1.189 & 0.16 \\
\hline $8 c$ & 0.416 & -0.427 & -0.006 & 0.844 & 0.22 \\
\hline
\end{tabular}

${ }^{a}$ glassy carbon electrode, $\mathrm{Ag} / \mathrm{AgCl}, \mathrm{Pt}$, sweep rate: $0.1 \mathrm{~V} \mathrm{~s}^{-1}$. Potentials were shown as vs. SHE. ${ }^{b}$ anodic peak potential. ${ }^{c}$ cathodic peak potential. ${ }^{d} E^{1 / 2}=\left(E_{p a}+E_{p c}\right) / 2 .{ }^{e} \Delta E=E_{p a}-E p c .{ }^{f}$ The peak currents $\left(i_{p a}\right.$ and $\left.i_{p c}\right)$ were measured from the respective baseline currents. Adapted with permission from (Yamasaki et al., J Org Chem 2011;76:435). Copyright (2012) American Chemical Society.

Table 2. Experimental redox potentials of nitroxide / deprotonated hydroxylamine redox couple ${ }^{a}$

(Kinoshita et al., 2009). This suggests that the electronic environment around the N-O moiety also influences its reduction stability. In fact, the rate of reduction of $\beta$ - or $\gamma$ substituted nitroxides by ascorbate has been reported to be primarily dependent upon their structure and correlation with $\mathrm{E}_{1 / 2}$ (Blinco et al., 2008; Kocherginsky and Swartz, 1995). The reactivity of $\alpha$-substituted nitronyl nitroxides is also dependent upon the electronic properties of the substituent groups ( $\mathrm{Wu}$ et al., 2006). The $\alpha$-substitution of piperidine nitroxide has been reported to change dramatically their redox potentials for one-electron oxidation and reduction (Yamasaki et al., 2011). In the oxidation step, electron-donating substituents are likely to stabilize oxoammonium cations, and substituents with heteroatoms destabilize them because of the electron-withdrawing inductive effect (Fig. 4, Table 1). The redox potentials for one-electron reduction are listed in Table 2. The electron-withdrawing groups at the $\alpha$-positions of the piperidine ring destabilize the reduced form of nitroxides, whereas electron-donating substituents stabilize them.

\subsection{Structure-reactivity relationships}

As described above, ascorbate can readily convert nitroxides into the corresponding hydroxylamines. The reduction rate is correlated with the inductive effects from the $\beta$ position in the piperidine ring and the $\gamma$-position in the pyrrolidine ring (Morris et al., 1991). 
Also, nitroxides with heteroatoms in their ring are unstable for the reduction (Couet et al., 1985).

Imidazole, isoindoline and piperidine nitroxides have a common feature: tetraethylnitroxides at $\alpha$-positions adjacent to the radical moiety have high resistance to reduction by ascorbate compared with the widely used tetramethyl-nitroxides (see above). The rate of decay of the ESR signals of nitroxides seems to be inversely proportional to the number of ethyl groups (Yamasaki et al., 2010). Nitroxides containing four ethyl groups are more resistant to the reduction than those with two ethyl groups. The reduction rates of nitroxides which have heteroatoms in their spirocyclohexyl ring have been found to be higher than tetramethyl nitroxides. Electron-withdrawing groups at spirocyclohexyl rings decrease the electron density around the N-O moiety, thereby favoring the reduction reaction. The trend of redox potentials for nitroxide reduction from electrochemical experiments is likely to be exactly the same as that of the nitroxide reduction rate by ascorbate. The ESR signal decay rate and the electromotive force between nitroxide and ascorbate $\left(\Delta \mathrm{E}_{\mathrm{N}-\mathrm{A}}\right)$ or the change in Gibbs free energy $(\Delta \mathrm{G})$ demonstrates very good correlations with $\Delta \mathrm{G}$ in the negative $\Delta \mathrm{G}$ region $\left(\mathrm{r}^{2}=0.988\right)$ (Fig. 5) (Yamasaki et al., 2010). This indicates that reduction of the nitroxide by ascorbate occurred spontaneously if the $\Delta G$ value is negative, and that the reduction is not spontaneous if the $\Delta G$ value is positive. The factors influencing the reduction process of the nitroxide are dependent not only upon steric hindrances but also on redox potentials. The $\alpha$-substitutions of piperidine nitroxides would be an effective approach to control the reactivity of nitroxides as a function of their applications.

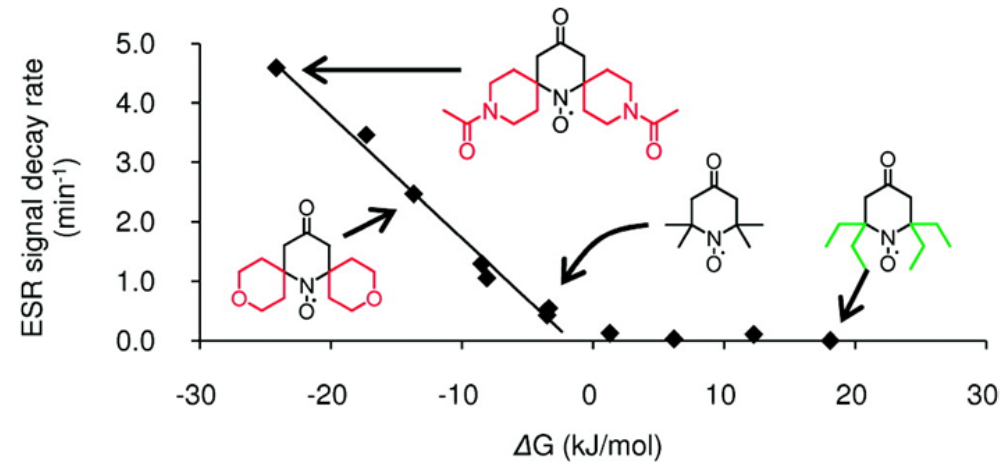

Figure 5. Relationship between the rates of decay of ESR signals and $\Delta \mathrm{G}$. $\Delta \mathrm{G}$ was calculated from $\Delta \mathrm{EN}-\mathrm{A}$ with use of the standard expression $\Delta \mathrm{G}=-\mathrm{nF} \Delta \mathrm{EN}_{\mathrm{N}-\mathrm{A}}$, where $\Delta \mathrm{E}_{\mathrm{N}-\mathrm{A}}$ is a subtraction of the redox potential of ascorbate from that of nitroxides, $\mathrm{n}$ is the number of electrons per mole of product, and $\mathrm{F}$ is the Faraday constant. The correlation coefficient when $\Delta \mathrm{G}$ was negative was 0.988 . Reprinted with permission from (Yamasaki et al., J Org Chem 2011;76:435). Copyright (2012) American Chemical Society)

\subsection{In vivo evaluation and imaging}

Nitroxides are reduced to mainly the hydroxylamine form in vivo by non-enzymatic processes involving gluthathione, the reduced form of nicotinamide adenine dinucleotide 
phosphate (NADPH), and ascorbic acid. Tetramethyl-nitroxides are widely used as biological reporters such as superoxide-dismutase mimics (Krishna et al., 1996), antioxidants (Wilcox and Pearlman, 2008) and radiation-protecting agents (Metz et al., 2004). However, non-specific reactions limit their applications to monitor changes in redox status. To increase their general versatility, improvement of the stability of nitroxides in vivo is important.

In general, the stability of nitroxide is reflected by their type of ring, substituent groups, and lipophilicity. Piperidine-nitroxides show a short half-life compared with that of pyrroridinenitroxides. A typical tetramethyl-piperidine nitroxide, Tempone (oxo-TEMPO), has a short life-time ( $\approx 2 \mathrm{~min}$ ) in blood due to rapid reduction (Ishida et al., 1989; Schimmack et al., 1976). However, piperidine nitroxides with spirocyclohexyl groups show resistance to enzymatic reduction in mouse liver homogenates (Okazaki et al., 2007). Conversely, tetraethyl nitroxides show resistance to reduction by ascorbic acid and seem to be stable in vivo. In fact, the half-lives of 4-oxo- and 4-hydroxy-2,2,6,6-tetraethyl-piperidine-1-oxyl in the mouse tail were $16.4 \pm 1.3 \mathrm{~min}$ and $20.0 \pm 3.0 \mathrm{~min}$, respectively, although that of carbamoylPROXYL was $8.5 \pm 2.7 \mathrm{~min}$ (Kinoshita et al., 2010). The factor influencing the reactivity of nitroxides to reductants is thought to be their redox potential. Also, higher inductive substitution constants at the 4-position of piperidine nitroxides were found to confer higher rate constants for ascorbic acid reduction, emphasizing the importance of the electronic effects of the substituents of nitroxides.

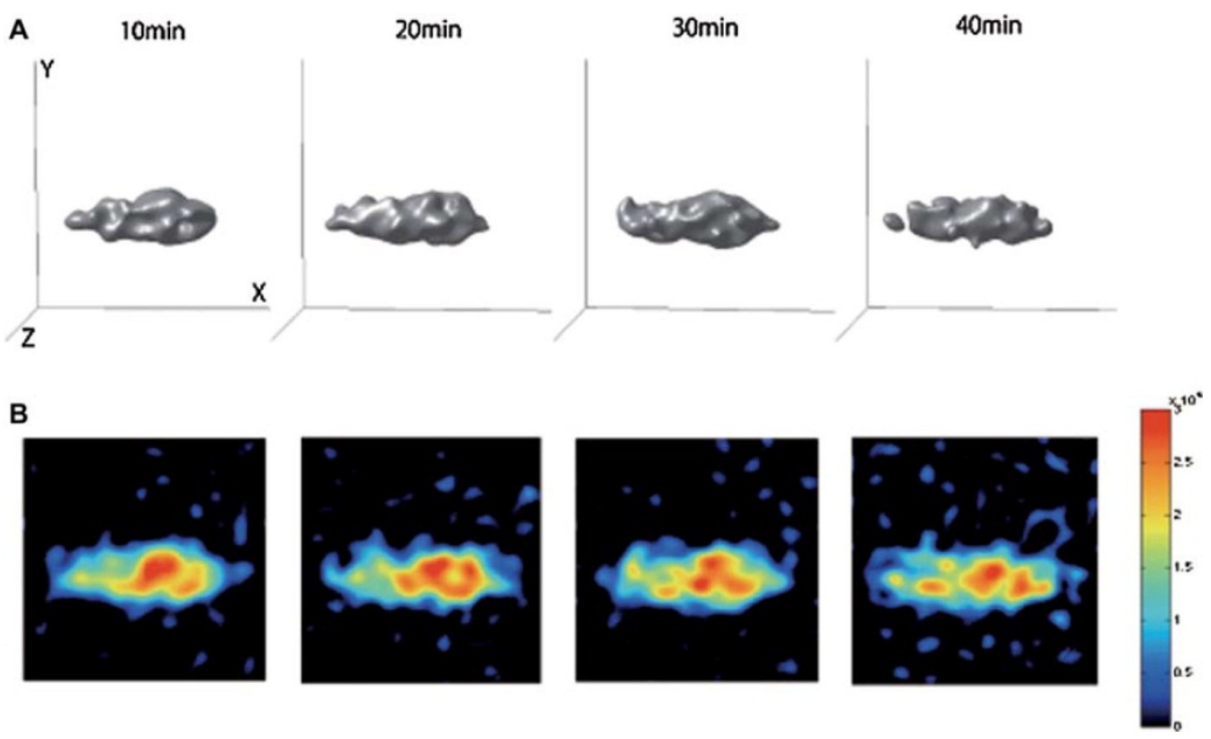

Figure 6. Temporal changes in three-dimensional surface-rendered EPR images (A) and twodimensional slice images (B) of TEEPONE in mouse brains. EPR images were obtained 10, 20, 30, and 40 min after intravenous injection of TEEPONE. (Emoto et al., Free Radic Res 2011;45: 1325, copyright $\odot$ ) 2012, Informa Healthcare. Reproduced with permission of Informa Healthcare) 
A nitroxide with a long half-life can also be a candidate in vivo imaging agent. In vivo evaluations have revealed that tetraethyl-nitroxides have several advantages for application as contrast agents for monitoring redox status: non-toxicity, lack of blood pressure-lowering effects, and stability in vivo. Recently, it has been reported that the half-life of 4-oxo-2,2,6,6tetraethyl-piperidine-1-oxyl (TEEPONE) obtained in mice brains is $81.1 \pm 0.7 \mathrm{~min}$, indicating that TEEPONE is more stable compared with other nitroxides that are readily converted into hydroxylamines in tissues (Fig. 6) (Emoto et al., 2011). The decay rate of TEEPONE has no relation with ascorbic acid reduction: this compound can effectively scavenge free radicals such as carbon- and oxygen-centered radicals.

\section{Conclusions}

Recently, various types of $\alpha$-substituted nitroxides have been synthesized and their in vivo and in-vitro characteristics evaluated. Introducing $\alpha$-substituent groups can modify and control their nature according to usage as spin probes, antioxidants, and contrast agents. Although tetramethyl-nitroxides have been widely used in physiological and biological systems, the unique properties of $\alpha$-substituted nitroxides will extend the possibilities of their applications. Development of $\alpha$-substituted nitroxides creates the possibility of expansion of their use in a wide range of fields.

\section{Author details}

Toshihide Yamasaki, Fumiya Mito, Yuta Matsuoka, Mayumi Yamato and Ken-ichi Yamada Faculty of Pharmaceutical Sciences, Kyushu University, Japan

\section{References}

Ankel, E.G.;Lai, C.S.;Hopwood, L.E. \& Zivkovic, Z. (1987). Cytotoxicity of commonly used nitroxide radical spin probes. Life Sci 40, 495-498.

Black, D.S.;Edwards, G.L.;Evans, R.H.;Keller, P.A. \& Laaman, S.M. (2000). Synthesis and Reactivity of 1-Pyrroline-5-carboxylate Ester 1-Oxides. Tetrahedron 56, 1889-1897.

Blinco, J.P.;Hodgson, J.L.;Morrow, B.J.;Walker, J.R.;Will, G.D.;Coote, M.L. \& Bottle, S.E. (2008). Experimental and theoretical studies of the redox potentials of cyclic nitroxides. $J$ Org Chem 73, 6763-6771.

Bobko, A.A.;Kirilyuk, I.A.;Grigor'ev, I.A.;Zweier, J.L. \& Khramtsov, V.V. (2007). Reversible reduction of nitroxides to hydroxylamines: Roles for ascorbate and glutathione. Free Radic Biol Med 42, 404-412.

Borbat, P.P.;Costa-Filho, A.J.;Earle, K.A.;Moscicki, J.K. \& Freed, J.H. (2001). Electron spin resonance in studies of membranes and proteins. Science 291, 266-269.

Chan, K.S.;Li, X.Z. \& Lee, S.Y. (2010). Ligand-Enhanced Aliphatic Carbon-Carbon Bond Activation of Nitroxides by Rhodium(II) Porphyrin. Organometallics 29, 28502856. 
Couet, W.R.;Brasch, R.C.;Sosnovsky, G. \& Tozer, T.N. (1985). Factors affecting nitroxide reduction in ascorbate solution and tissue homogenates. Magn Reson Imaging 3, 8388.

Emoto, M.;Mito, F.;Yamasaki, T.;Yamada, K.I.;Sato-Akaba, H.;Hirata, H. \& Fujii, H. (2011). A novel ascorbic acid-resistant nitroxide in fat emulsion is an efficient brain imaging probe for in vivo EPR imaging of mouse. Free Radic Res 45, 1325-1332.

Fairfull-Smith, K.E.;Brackmann, F. \& Bottle, S.E. (2009). The Synthesis of Novel Isoindoline Nitroxides Bearing Water-Solubilising Functionality. Eur J Org Chem 2009, 1902-1915.

Griffiths, P.;Moad, G. \& Rizzardo, E. (1983). Synthesis of the radical scavenger 1,1,3,3Tetramethylisoindolin-2-yloxyl. Aust J Chem 36, 397-401.

Ikuma, N.;Tamura, R.;Shimono, S.;Kawame, N.;Tamada, O.;Sakai, N.;Yamauchi, J. \& Yamamoto, Y. (2004). Magnetic Properties of All-Organic Liquid Crystals Containing a Chiral Five-Membered Cyclic Nitroxide Unit within the Rigid Core. Angew Chem Int Ed 43, 3677-3682.

Ishida, S.;Kumashiro, H.;Tsuchihashi, N.;Ogata, T.;Ono, M.;Kamada, H. \& Yoshida, E. (1989). In vivo analysis of nitroxide radicals injected into small animals by L-band ESR technique. Phys Med Biol 34, 1317-1323.

Keana, J.F.W.;Seyedrezai, S.E. \& Gaughan, G. (1983). Difunctionalized trans-2,5disubstituted pyrrolidine (azethoxyl) nitroxide spin-labels. J Org Chem 48, 26442647.

Kinoshita, Y.;Yamada, K.;Yamasaki, T.;Mito, F.;Yamato, M.;Kosem, N.;Deguchi, H.;Shirahama, C.;Ito, Y.;Kitagawa, K.;Okukado, N.;Sakai, K. \& Utsumi, H. (2010). In vivo evaluation of novel nitroxyl radicals with reduction stability. Free Radic Biol Med 49, 1703-1709.

Kinoshita, Y.;Yamada, K.;Yamasaki, T.;Sadasue, H.;Sakai, K. \& Utsumi, H. (2009). Development of novel nitroxyl radicals for controlling reactivity with ascorbic acid. Free Radic Res 43, 565-571.

Kirilyuk, I.A.;Bobko, A.A.;Grigor'ev, I.A. \& Khramtsov, V.V. (2004). Synthesis of the tetraethyl substituted $\mathrm{pH}$-sensitive nitroxides of imidazole series with enhanced stability towards reduction. Org Biomol Chem 2, 1025-1030.

Kocherginsky, N. \& Swartz, H.M. (1995). Nitroxide Spin Labels: Reactions in Biology and Chemistry.

Krishna, M.C.;Grahame, D.A.;Samuni, A.;Mitchell, J.B. \& Russo, A. (1992). Oxoammonium cation intermediate in the nitroxide-catalyzed dismutation of superoxide. Proc Natl Acad Sci U S A 89, 5537-5541.

Krishna, M.C.;Russo, A.;Mitchell, J.B.;Goldstein, S.;Dafni, H. \& Samuni, A. (1996). Do nitroxide antioxidants act as scavengers of O2-. or as SOD mimics? J Biol Chem 271, 26026-26031. 
Kuppusamy, P.;Li, H.;llangovan, G.;Cardounel, A.J.;Zweier, J.L.;Yamada, K.;Krishna, M.C. \& Mitchell, J.B. (2002). Noninvasive imaging of tumor redox status and its modification by tissue glutathione levels. Cancer Res 62, 307-312.

Le Moigne, F.;Mercier, A. \& Tordo, P. (1991). $\beta$-Phosphorylated cyclic nitroxides. 2. Synthesis of pyrrolidin- and piperidin-2-yl phosphonates and the corresponding stable nitroxides. Tetrahedron Lett 32, 3841-3844.

Ma, Z.;Huang, Q. \& Bobbitt, J.M. (1993). Oxoammonium salts. 5. A new synthesis of hindered piperidines leading to unsymmetrical TEMPO-type nitroxides. Synthesis and enantioselective oxidations with chiral nitroxides and chiral oxoammonium salts. J Org Chem 58, 4837-4843.

Mannan, M.A.;Ichikawa, A. \& Miura, Y. (2007). Living radical polymerization of styrene mediated by a piperidinyl-N-oxyl radical having very bulky substituents. Polymer 48 , 743-749.

Marx, L.;Chiarelli, R.;Guiberteau, T. \& Rassat, A. (2000). A comparative study of the reduction by ascorbate of 1,1,3,3-tetraethylisoindolin-2-yloxyl and of 1,1,3,3tetramethylisoindolin-2-yloxyl. J Chem Soc, Perkin Trans 1, 1181-1182.

Mathieu, C.;Mercier, A.;Witt, D.;Debmkowski, L. \& Tordo, P. (1997). beta-phosphorylated nitroxides in the pyrrolidine series: reduction by ascorbate. Free Radic Biol Med 22, 803806.

Metz, J.M.;Smith, D.;Mick, R.;Lustig, R.;Mitchell, J.;Cherakuri, M.;Glatstein, E. \& Hahn, S.M. (2004). A phase I study of topical Tempol for the prevention of alopecia induced by whole brain radiotherapy. Clin Cancer Res 10, 6411-6417.

Miura, Y.;Ichikawa, A. \& Taniguchi, I. (2003). 'Living' radical polymerization of styrene mediated by spiro ring-substituted piperidinyl-N-oxyl radicals. The effect of the spiro rings on the control of polymerization. Polymer 44, 5187-5194.

Miura, Y.;Nakamura, N. \& Taniguchi, I. (2001). Low-Temperature "Living" Radical Polymerization of Styrene in the Presence of Nitroxides with Spiro Structures. Macromolecules 34, 447-455.

Morris, S.;Sosnovsky, G.;Hui, B.;Huber, C.O.;Rao, N.U.M. \& Swartz, H.M. (1991). Chemical and electrochemical reduction rates of cyclic nitroxides (nitroxyls). J Pharm Sci 80, 149152.

Murayama, K.;Morimura, S.;Amakasu, O.;Toda, T. \& Yamao, E. (1969). Convenient Synthetic Methods of 2,2,6,6-Tetramethyl-4-piperidone. Nippon kagaku zassi 90, 296299.

Okazaki, S.;Mannan, M.A.;Sawai, K.;Masumizu, T.;Miura, Y. \& Takeshita, K. (2007). Enzymatic reduction-resistant nitroxyl spin probes with spirocyclohexyl rings. Free Radic Res 41, 1069-1077.

Sakai, K.;Yamada, K.-i.;Yamasaki, T.;Kinoshita, Y.;Mito, F. \& Utsumi, H. (2010). Effective 2,6substitution of piperidine nitroxyl radical by carbonyl compound. Tetrahedron 66, 23112315. 
Saphier, O.;Silberstein, T.;Shames, A.I.;Likhtenshtein, G.I.;Maimon, E.;Mankuta, D.;Mazor, M.;Katz, M.;Meyerstein, D. \& Meyerstein, N. (2003). The reduction of a nitroxide spin label as a probe of human blood antioxidant properties. Free Radic Res 37, 301308.

Schimmack, W.;Deffner, U. \& Michailov, M.C. (1976). E.s.r study of the decay of the nitroxyl free radical TAN in whole rats and rat-tissue homogenates. Int J Radiat Biol Relat Stud Phys Chem Med 30, 393-397.

Schulte, T.;Siegenthaler, K.O.;Luftmann, H.;Letzel, M. \& Studer, A. (2005). NitroxideMediated Polymerization of N-Isopropylacrylamide: Electrospray Ionization Mass Spectrometry, Matrix-Assisted Laser Desorption Ionization Mass Spectrometry, and Multiple-Angle Laser Light Scattering Studies on Nitroxide-Terminated Poly-Nisopropylacrylamides. Macromolecules 38, 6833-6840.

Soule, B.P.;Hyodo, F.;Matsumoto, K.;Simone, N.L.;Cook, J.A.;Krishna, M.C. \& Mitchell, J.B. (2007). The chemistry and biology of nitroxide compounds. Free Radic Biol Med 42, $1632-$ 1650.

Volodarsky, L.B. \& Igor A, G.e. (1988). Synthesis of Heterocyclic Nitroxides. In Imidazoline Nitroxides, L.B. Volodarsky, ed. (Boca Raton: CRC Press), 5-28.

Wetter, C.;Gierlich, J.;Knoop, C.A.;Müller, C.;Schulte, T. \& Studer, A. (2004). Steric and Electronic Effects in Cyclic Alkoxyamines-Synthesis and Applications as Regulators for Controlled/Living Radical Polymerization. Chem Eur J 10, 1156-1166.

Wilcox, C.S. \& Pearlman, A. (2008). Chemistry and antihypertensive effects of tempol and other nitroxides. Pharmacol Rev 60, 418-469.

Wu, Y.;Bi, L.;Bi, W.;Li, Z.;Zhao, M.;Wang, C.;Ju, J. \& Peng, S. (2006). Novel 2-substituted nitronyl nitroxides as free radical scavengers: synthesis, biological evaluation and structure-activity relationship. Bioorg Med Chem 14, 5711-5720.

Yamada, K.;Yamamiya, I. \& Utsumi, H. (2006). In vivo detection of free radicals induced by diethylnitrosamine in rat liver tissue. Free Radic Biol Med 40, 2040-2046.

Yamasaki, T.;Ito, Y.;Mito, F.;Kitagawa, K.;Matsuoka, Y.;Yamato, M. \& Yamada, K.-i. (2011). Structural Concept of Nitroxide As a Lipid Peroxidation Inhibitor. J Org Chem 76, 41444148 .

Yamasaki, T.;Mito, F.;Ito, Y.;Pandian, S.;Kinoshita, Y.;Nakano, K.;Murugesan, R.;Sakai, K.;Utsumi, H. \& Yamada, K.-i. (2010). Structure-Reactivity Relationship of Piperidine Nitroxide: Electrochemical, ESR and Computational Studies. J Org Chem 76, 435-440.

Yan'shole, V.;Kirilyuk, I.;Grigor'ev, I.;Morozov, S. \& Tsentalovich, Y. (2010). Antioxidative properties of nitroxyl radicals and hydroxyamines in reactions with triplet and deaminated kynurenine. Russ Chem Bull 59, 66-74.

Yoshioka, T.;Higashide.S \& Murayama, K. (1972). Studies on Stable Free-Radicals .8. Synthesis and Oxidation of Hindered 4-Oxopiperidine Derivatives. Bull Chem Soc Japan 45, 636-638. 
Zubenko, D.;Tsentalovich, Y.;Lebedeva, N.;Kirilyuk, I.;Roshchupkina, G.;Zhurko, I.;Reznikov, V.;Marque, S.R.A. \& Bagryanskaya, E. (2006). Laser Flash Photolysis and CIDNP Studies of Steric Effects on Coupling Rate Constants of Imidazolidine Nitroxide with Carbon-Centered Radicals, Methyl Isobutyrate-2-yl and tert-Butyl Propionate-2-yl. J Org Chem 71, 6044-6052. 